\title{
Delayed administration of ixazomib modifies the immune response and prevents chronic graft-versus-host disease
}

\author{
Teresa Lopes Ramos $\mathbb{D}^{1,2}$, Estefanía García-Guerrero ${ }^{1}$, Teresa Caballero-Velázquez $\mathbb{D}^{1,3}$, Alfonso Rodríguez-Gil ${ }^{1}$, Rocío Caracuel-García ${ }^{1}$,
} Melanie Nufer ${ }^{1}$, María José Robles-Frías ${ }^{1}$, María Victoria Barbado ${ }^{1}$ and José A. Pérez-Simón (iD) ${ }^{1,3 凶}$

(c) The Author(s) 2021

In this study, we aimed to modify the immune response in the long term after allogeneic bone marrow transplantation (allo-BMT) by using the proteasome inhibitor ixazomib (IXZ) at the late stages of the post-transplant period. This approach facilitated the immune reconstitution after transplantation. IXZ significantly prolonged survival and decreased the risk of chronic graft-versus-host disease (cGvHD) in two different murine models without hampering the graft-versus-leukemia (GvL) effect, as confirmed by bioluminescence assays. Remarkably, the use of IXZ was related to an increase of regulatory T cells both in peripheral blood and in the GvHD target organs and a decrease of effector donor T cells. Regarding B cells, IXZ treated mice had faster recovery of B cells in $\mathrm{PB}$ and of pre-pro-B cells in the bone marrow. Mice receiving ixazomib had a lower number of neutrophils in the GvHD target organs as compared to the vehicle group. In summary, delayed administration of IXZ ameliorated cGvHD while preserving GvL and promoted a pro-tolerogenic immune response after allo-BMT.

Bone Marrow Transplantation (2021) 56:3049-3058; https://doi.org/10.1038/s41409-021-01452-1

\section{INTRODUCTION}

Although survival rates have improved over the years, a large proportion of patients undergoing allogeneic hematopoietic stem cell transplantation (allo-HSCT) still develop graft-versus-host disease (GvHD) [1-4], which is the main cause of death and markedly affects the quality of life after allo-HSCT $[5,6]$. The most effective strategies to prevent GvHD are based on the use of T cell depletion $[7,8]$. The effectiveness of allo-HSCT is based on the allorecognition of donor T cells, which induces a cytotoxic effect on tumor cells from the host (graft-versus-leukemia effect, GvL). Thus, the same mechanism of allorecognition is responsible for both GvHD and GvL, therefore any procedure aimed to prevent GvHD by increasing immunosuppressive treatment might affect GVL $[9,10]$.

Overall, risk profiles are similar for both acute and chronic GvHD [11]. Prior aGvHD is the main risk factor to develop cGvHD, but other risk factors also play an important role, such as the impact of donor sex or age and the use of mobilized peripheral blood cells are risk factors of chronic but not for aGvHD $[3,4]$

The pathogenesis of acute GvHD has been well characterized. In the case of chronic GvHD, the disease develops as a result of complex molecular/biology networks, from tissue damage to unusual antigen presentation and aberrant myeloid and lymphoid (T and B cell) interactions [12].

Recently, a 3-step model has been proposed to explain the pathophysiology of CGvHD. Phase I is the initial phase and is an effect of early post-transplant inflammation and tissue injury. The release of inflammatory cytokines activates antigen-presenting cells (APC) that consequently stimulate the activation of donor allo-reactive $T$ cells with an enhanced Th1/Tc1 and Th17/Tc17 T cell effector lineages and macrophages sequestration in tissues. Phase II is characterized by the presence of chronic inflammation and dysregulation of the immune system that cannot be counterbalanced by the regulatory immune responses. The dysregulated immunity and aberrant tissue repair can lead to the propagation of fibrosis. Phase 3 , aberrant repair mechanisms promote the release of profibrotic mediators by monocytes and macrophages, leading to fibroblast activation and collagen deposition and fibrosis [12-16].

The differences in the pathophysiology between acute and chronic GvHD might allow to design of specific approaches for cGvHD prophylaxis without increasing immune suppression or abrogating the alloreactive immune response early after transplantation. For this purpose, we aimed to target the cell subsets involved in cGvHD development. Remarkably, NF-kB plays a key role in the activation of $T$ or $B$ cells, macrophages, and dendritic cells [17]. Regarding lymphocytes, NF-KB is involved in pathways downstream $T$ and $B$ cell receptors [17-19]. APC cells also depend on NF-KB to become fully activated through Toll-like receptors (TLR) [17]. Proteasome inhibitors block the activation of NF-KB. Bortezomib (Bz) exerts a potent pro-apoptotic effect on activated T cells, preserving the viability of resting T-lymphocytes and regulatory $T$ cells (Treg) [20-22], and prevent GvHD both in preclinical and in clinical models [23-25].

Next generations of proteasomes inhibitors have been developed with different toxicity profiles compared with bortezomib. Ixazomib (IXZ) is an orally bioavailable inhibitor of the $20 \mathrm{~S}$

\footnotetext{
${ }^{1}$ Instituto de Biomedicina de Sevilla (IBIS/CSIC), CIBERONC, Universidad de Sevilla, Sevilla, Spain. ${ }^{2}$ Division of Blood and Marrow Transplantation, Stanford University School of

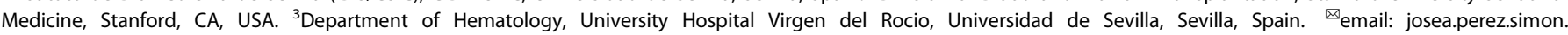
sspa@juntadeandalucia.es

Received: 23 March 2021 Revised: 9 August 2021 Accepted: 25 August 2021

Published online: 23 September 2021 
proteasome. This drug has similar selectivity and potency to Bz in biochemical and cell-based assays, but with the advantage that it has a shorter $20 \mathrm{~S}$ proteasome dissociation half-life. In addition to $\mathrm{NF}-\mathrm{kB}$, proteasome inhibitors affect other pathways involved in immune cells activation and viability [26-28].

In this study, we aimed to challenge the classic approach of preventing $\mathrm{CGvHD}$ by focusing on the abrogation of the immune response in the early post-transplant period. Since most pathophysiological mechanisms leading to CGvHD are triggered early but are perpetuated late after transplant, we hypothesized that new approaches could be designed to modify the immune response at later stages of the transplant period to favor a tolerogenic immune response. For this purpose, we evaluated a delayed administration of IXZ confirming its efficacy in ameliorating the incidence of delay/progressive chronic GvHD without hampering GvL.

\section{METHODS \\ Mice}

BALB/C $\left(H-2^{d}\right)$ and C57BL/6 $\left(H-2^{b}\right)$ and B10.D2 $\left(H-2^{d}\right)$ mice were purchased from Charles River Laboratories (Morrisville, NC). The green fluorescent protein (GFP) C57BI/6-Tg(ACTB-EGFP)1Osb/J) $\left(\mathrm{H}-2^{\mathrm{b}}\right)$ [29] were housed in the animal facility. All experiments were performed with sex-matched animals and mice were between 7-10 weeks of age. Mice were held under specific pathogen-free conditions. Animal protocols were approved by the Institutional Animal Care and Use Committee at the Institute of Biomedicine in Seville.

\section{GvHD model}

For progressive chronic GvHD (pcGvHD), recipient mice (BALB/c) were irradiated with $8.6 \mathrm{~Gy}$ split into 2 doses. To induce GvHD, irradiated recipients received $5 \times 10^{6}$ bone marrow (BM) cells and $2 \times 10^{6}$ donor splenocytes (SC) cells, previously cultured at $37^{\circ} \mathrm{C}$ for $2 \mathrm{~h}$ from C57BI/6$\mathrm{Tg}$ donor on day 0 . This model was based on previous reports $[16,30,31]$ which described $C$ GvHD features in the long term by infusing a low number of splenocytes. In our model, the recipient mice showed signs of acute GvHD starting around day +20 posttransplantation. Around day +49 surviving mice started to gain weight and develop new skin lesions and alopecia. Histological examination confirmed the presence of chronic signals in the different target organs (Supplementary Fig. 1).

For the sclerodermatous CGvHD model (scGvHD), BALB/c mice received lethal total body irradiation (10 Gy) split into 2 doses of $5 \mathrm{~Gy}, 24 \mathrm{~h}$ apart. BM cells $\left(10 \times 10^{6}\right.$ cells) with SC cells $\left(15 \times 10^{6}\right.$ cells) from B10.D2 donor mice $\left(\mathrm{H} 2^{\mathrm{d}}\right)$ were intravenously infused into lethally irradiated, major $\mathrm{MHC}$ identical, minor histocompatibility antigen-mismatched recipient BALB/C $\left(\mathrm{H}^{\mathrm{d}}{ }^{\mathrm{d}}\right)$ mice.

Recipients were monitored daily, body weight and GvHD signs were assessed twice applying standardized scoring. The scoring system includes the following parameters: weight loss, posture, activity, fur texture, and skin integrity (maximum index of 10). The criteria for euthanasia were based on clinical scores and tumor-related symptoms $[23,32]$. Prior studies have shown that in acute/chronic GvHD model cohorts of 5-8 animals per group. To detect the significant impact of the treatment we elected to perform three independent experiments with 8 to 12 mice per group. Mice reaching a GvHD score of $8 / 10$ were sacrificed in agreement with the request of the ethical committee. The scores and weight of these animals were kept in the data set and the euthanized animals were counted as dead in the survival curves. The mice that died before starting the treatment were excluded from the experiment.

Ixazomib (IXZ) was dissolved in 5\% of 2-hydroxypropyl- $\beta$-cyclodextrin (Sigma-Aldrich). IZX at $1 \mathrm{mg} / \mathrm{Kg}$ starting on day +21 for pcGvHD and at 3 $\mathrm{mg} / \mathrm{Kg}$ from day +30 in the scGvHD model was administered subcutaneously two times per week until the end of the experiment. Cyclosporine A (CsA)-treated mice received $5 \mathrm{mg} / \mathrm{kg}$ intraperitoneally (IP) from day -1 until day 120 days post-transplant, five times a week. The control groups received vehicle solutions according to the same schedule as the treatment group. The technician without interest in the study outcome randomizes the mice for the experiment. To avoid bias, in the same cage there were animals that received the drug and others the vehicle. No blinding was done during the treatment and GvHD scorings.

\section{Graft-versus-leukemia assays and bioluminescence imaging}

In vivo bioluminescence imaging was performed as previously described [33] with an IVIS Lumina III in vivo imaging system (PerkinElmer, Massachusetts, USA). Images were analyzed with Living Image Software 3.2 (Caliper Life Sciences). A20 (B cell lymphoma) cell line was acquired from American Tissue Culture Collection (ATCC; TIB-208) and transfected with luciferase and GFP. The cells were injected into recipient $B A L B / c$ mice intravenously at a dose of $0.5 \times 10^{6}$ cells. A20 cells were injected at day 0 after BMT as described. Tumor growth was monitored once a week using an IVIS imaging system.

\section{Histopathological examination and tissue digestion}

Detailed information, including tissue digestion and histology, is provided in supplementary methods.

\section{Flow cytometry assays}

Flow cytometry analysis methodology is provided in supplementary methods.

\section{Statistics}

For murine GvHD survival experiments, the differences in animal survival (Kaplan-Meier survival curves) were analyzed by the Mantel-Cox test.

For statistical analysis of 2 groups, an unpaired 2-tailed Student's $t$-test was applied. All data were tested for normality applying the KolmogorovSmirnov test. If the data did not meet the criteria of normality, the MannWhitney $U$ test was applied. When more than 2 groups were analyzed, we used the Kruskal-Wallis test if nonparametric testing was suggested, and we performed a 1-way ANOVA in case of normally distributed data.

All data are shown as mean \pm standard error of the mean (SEM) and represent a combined data from at least three independent experiments. Figures were prepared using GraphPad Prism 5.

$P$ values $<0.05\left({ }^{*}\right),<0.001\left({ }^{* *}\right)$, and $<0.001\left({ }^{* * *}\right)$ were considered significant.

\section{RESULTS}

Ixazomib decreases the risk and severity of progressive chronic GvHD and improves survival in a murine model Using a GvHD model of C57BL/6 donor into MHC-mismatched $B A L B / c$ recipient, we evaluated the effect of Ixazomib (IXZ) on pcGvHD (Fig. 1). Treatment with IXZ significantly prolonged survival as compared to those mice that received only vehicle (designed as untreated transplanted mice: UTM) $(P=0.001)$ (Fig. 1A). IXZ treatment also attenuated the clinical signs of GvHD and weight loss (Fig. 1B). Next, we evaluated the combination of IXZ plus cyclosporine $A(C s A)$ at $5 \mathrm{mg} / \mathrm{Kg}$, the latter being started on $\mathrm{d}-1$. All treatment groups had improved survival when compared with the UTM, the combination being significantly better as compared to either drug alone (Supplementary Fig. 2). Prolonged administration (14 weeks) of IXZ did not delay platelet or white blood cell recovery after transplantation (Supplementary Fig. 3), thus showing that IXZ administration efficiently protected mice from pcGvHD without significant myelotoxicity.

Next, we used a murine model of sclerodermatous cGvHD (scGvHD) [34]. Recipient mice were treated either with vehicle (UTM) or IXZ from day +30 after transplantation, the time when the signs of scGvHD start. Treatment with IXZ significantly decreased the formation of skin lesions, alopecia, and mobility score, with a significant reduction of the overall cGvHD score when compared to UTM (Fig. 1C, D).

Histologic features were analyzed in both models in GvHD target organs. Regarding pcGvHD, large bowel crypt structures were severely disturbed with an increased number of apoptotic bodies, cryptal abscesses, and the presence of inflammatory cells. In the liver, ductopenia was observed together with diffuse 

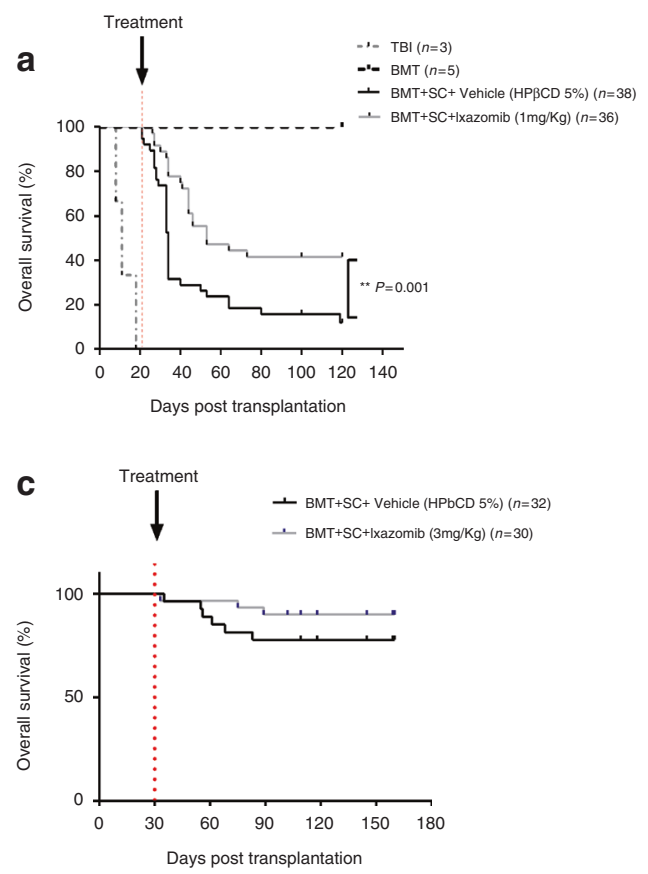

e

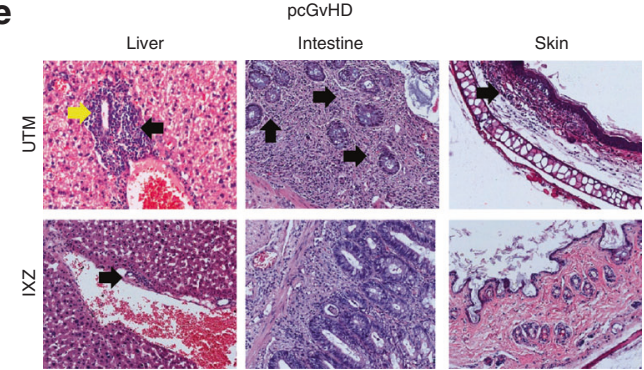

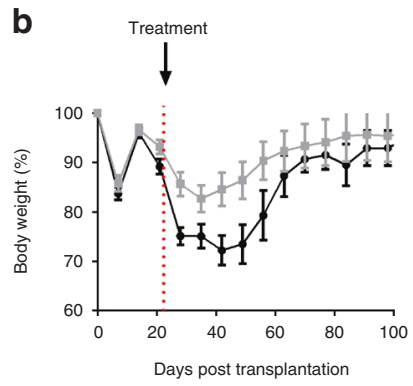

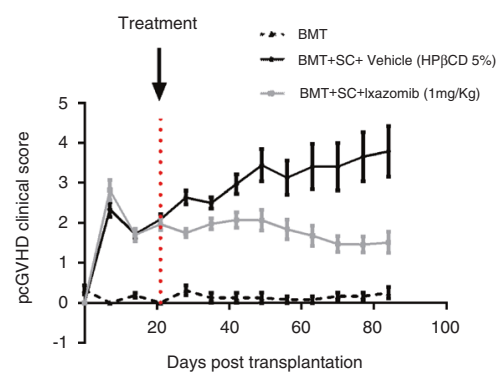

d
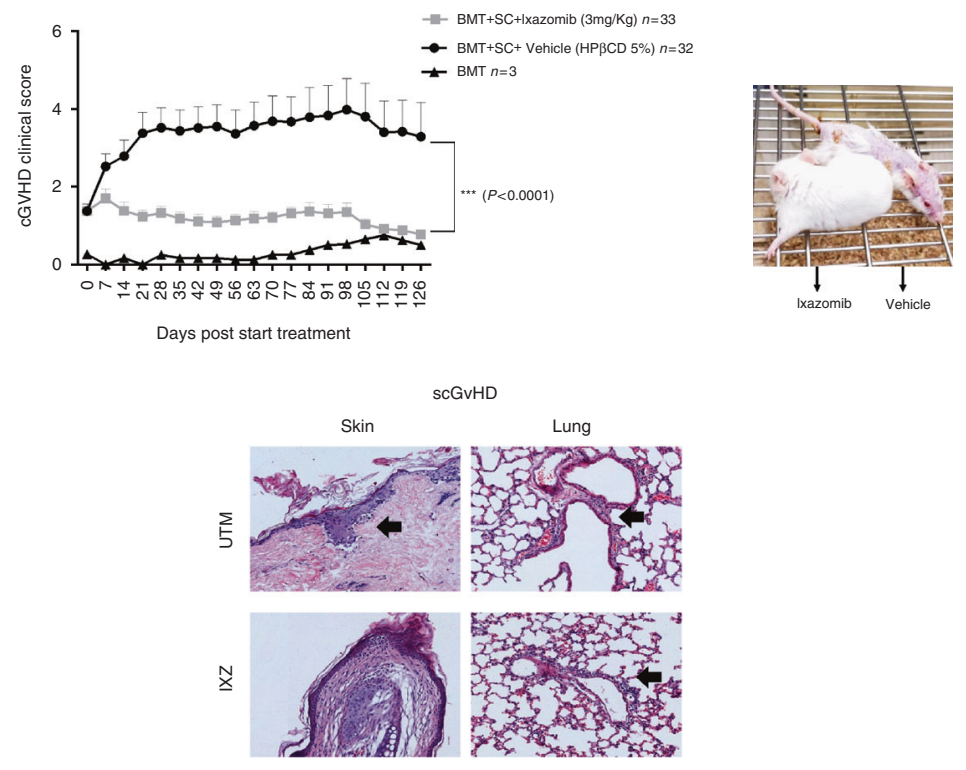
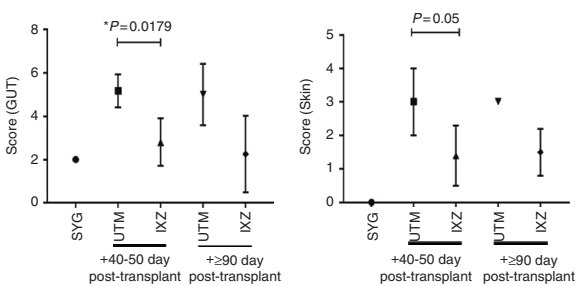
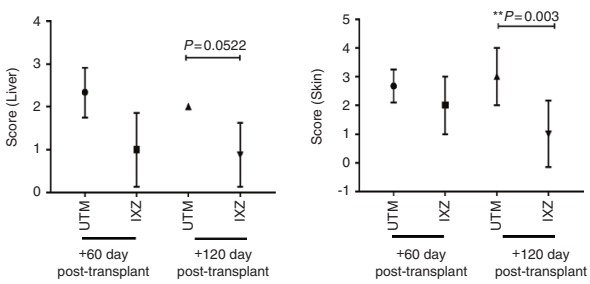

Fig. 1 Ixazomib administration increases the survival and protects mice from progressive chronic and sclerodermatous chronic GvHD. Effect of IXZ on pcGvHD in a murine model. A Kaplan-Meier survival curves of mice receiving IXZ at $1 \mathrm{mg} / \mathrm{Kg}$, two times a week subcutaneously from day +21 post-transplantation or vehicle. B clinical score and weight of mice receiving IXZ versus untreated transplanted mice (UTM). In all experiments, UTM received the vehicle of the drug. C For scGvHD, recipient BALB/c mice were randomized to receive vehicle (UTM) (HP $\beta C D 5 \%$ ) or IXZ (3 mg/Kg) subcutaneously from day +30 after transplant. Kaplan-Meier survival curves of mice receiving IXZ or vehicle (UTM) are shown. D represents the clinical score of mice receiving IXZ versus UTM. Photographs were taken on day +80 after HSCT from scGvHD mice treated with vehicle or IXZ. E Scores were evaluated in the intestine, colon, skin, and liver using a semi-quantitative score by pathologists in a blind code fashion. Histopathology analysis of liver, large and small bowel, skin, and liver samples from the different experimental groups are shown. In the pcGvHD it was observed the presence of lymphocytic infiltration in periportal areas (black arrows) with the loss of bile duct (yellow arrows), loss of crypts in the large bowel (black arrows), vacuolar degeneration in the skin (black arrows). scGvHD: Presence of fissures in the skin and the presence of perivascular inflammatory infiltrate in the lung. Data are shown as mean \pm standard error of the mean (SEM). Data are collected from 4-5 independent experiments with 5-6 mice per group. Student's $t$-test ${ }^{*} P<.05$, ${ }^{* *} P<.01$, and ${ }^{* * *} P<.001$ were considered significant. BMT: bone marrow transplantation; SC: splenocytes; TBI: total body irradiation. UTM: untreated transplanted mice (vehicle administration); IXZ: ixazomib group; HD: healthy donor; SYG: syngeneic group. Original magnification: $\times 200$.

microvesicular steatosis with lymphocytic infiltration in periportal areas. In the skin, fibrosis and atrophy of adnexal structures were observed. Treatment with IXZ significantly decreased the overall GvHD histopathological score (Fig. 1E) on day 40-50 posttransplantation, with the most pronounced differences observed in the gut $(P=0.0179)$ and liver $(P=0.0179)$. As far as the histopathological score in the scGvHD model is concerned, phenotypic hallmarks of cGvHD were also observed in the skin, with epidermal atrophy, dermal fat loss, hair follicle destruction, and mononuclear cell infiltration. The other target organs analyzed also showed pathological involvement. IXZ decreased histopathological scores in both times points analyzed (Fig. 1E). These results confirmed a protective effect of IXZ on CGvHD development. 
The use of Ixazomib was associated with a faster recovery of a normal pattern of $T$ cell subpopulations post-transplant and a significant increase of regulatory $T$ cells

Once we confirmed the effect of IXZ on the pcGvHD in vivo, we analyzed the different immune cell subpopulations reconstitution once donor complete chimerism was confirmed, as assessed by the presence of donor cells (GFP+) (Supplementary Fig. 4)

Upon analyzing the expression of CD44 and CD62L in CD4 ${ }^{+}$ and $\mathrm{CD}^{+}{ }^{\mathrm{T}}$ cells, we evaluated naïve, effector, and memory $\mathrm{T}$ cell subpopulations along with transplantation. We observed an increase of effector $T$ cells $\left(T_{E F / E M}\right)$ after allo-transplant cells when compared to healthy donors (HD) and mice transplanted from a syngeneic donor (SYG). After 4 weeks of IXZ treatment, a significant decrease of $\mathrm{CD}^{+}$and $\mathrm{CD}^{+}$effector $\mathrm{T}$ cells in the PB, spleen, and LN was observed when compared with the group that received vehicle (UTM). Similar behavior was observed in the other GvHD target organs analyzed (Fig. 2A). Interestingly, 10 weeks after starting treatment, mice receiving IXZ displayed a similar pattern of effector cells as compared to the HD and SYG groups, with the exception of the LN. There was still observed an increase of effector $\mathrm{CD}^{+}{ }^{+} \mathrm{T}$ cells. In the spleen, a decrease of effector $\mathrm{CD}^{+} \mathrm{T}$ cells was followed by a decrease of IFN- $\gamma$ (Supplementary Fig. 5).

In addition, a significant reduction in the percentage of $\mathrm{CD}^{+}$ $\mathrm{CD}^{+}$thymocytes (DP) was observed in UTM mice, a distinctive hallmark of thymus GvHD [35]. IXZ group showed a significant increase of DP as compared with UTM (Fig. 2B).

We and others have previously described that proteasome inhibitors can purge alloreactive $\mathrm{T}$ cells but preserve regulatory T cells (Treg) [21]. Interestingly, treatment with IXZ significantly increased the percentage of $\mathrm{CD}_{4} 5^{+} \mathrm{CD}^{+} \mathrm{CD}^{+} \mathrm{CD}^{+} 5^{+} \mathrm{FOXP}^{+}$ cells in PB and in the different organs analyzed (Fig. 3). The a
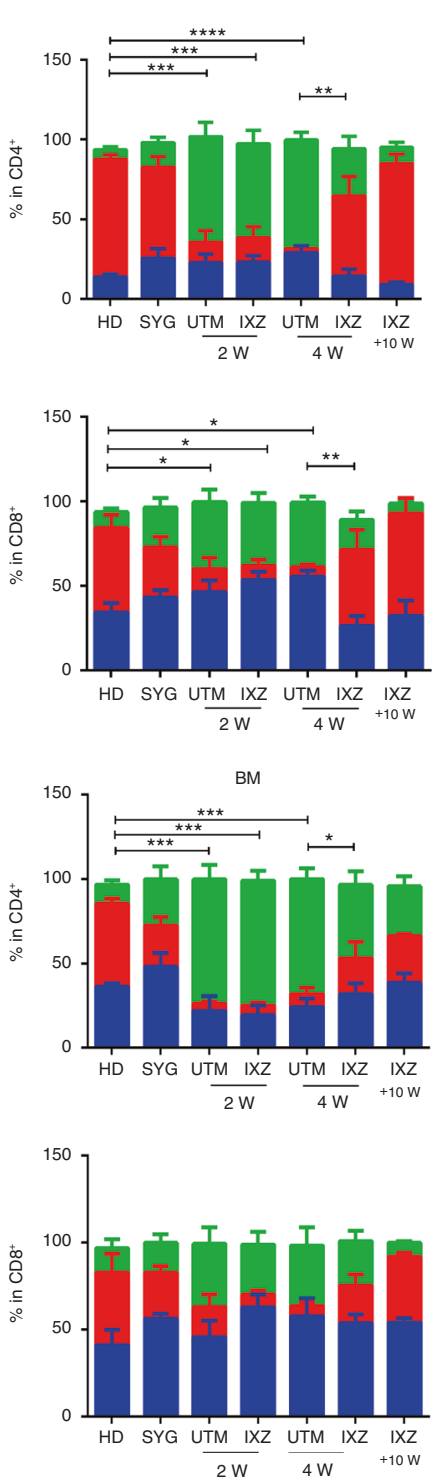
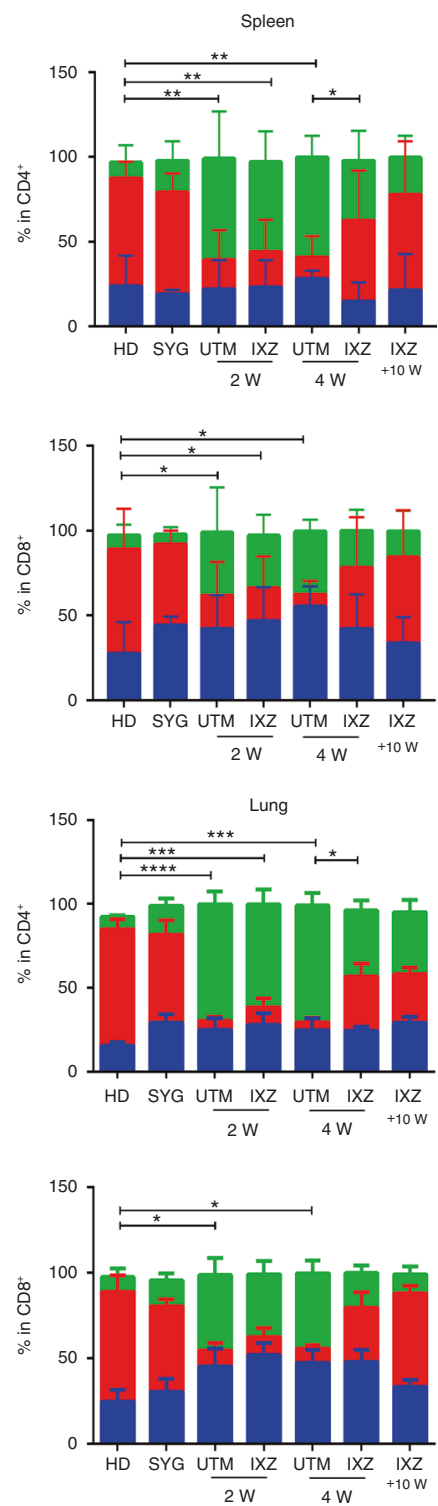
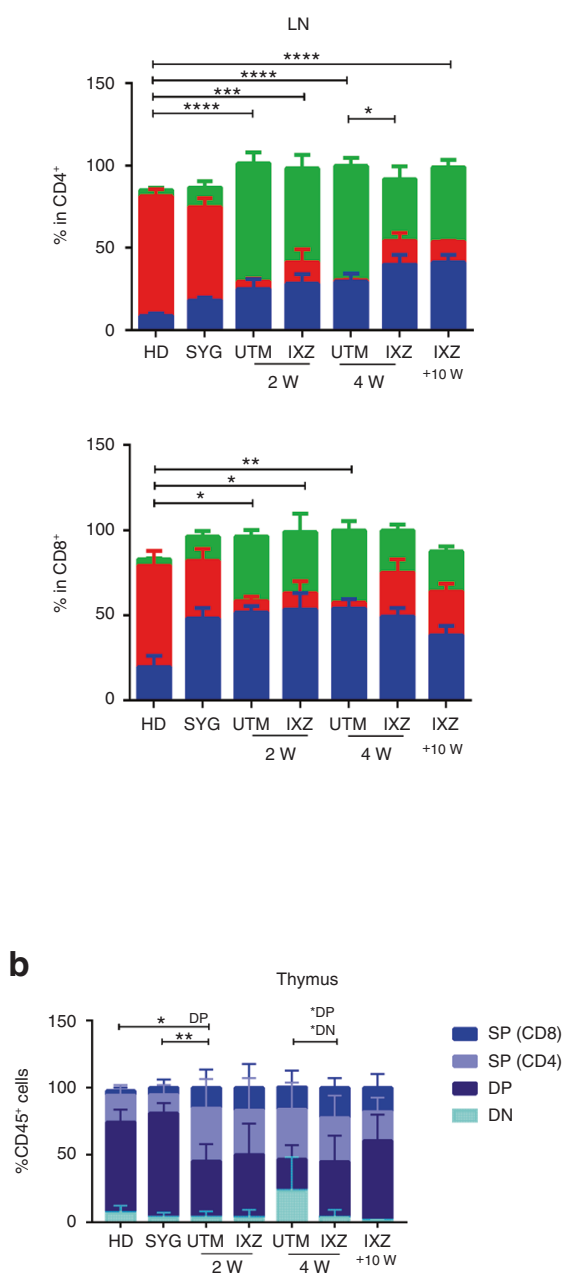

Fig. 2 Ixazomib treatment significantly decreases the T effector cells in pcGvHD model. Flow cytometry assays of the different organs at

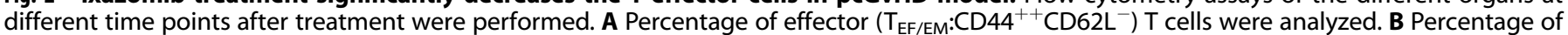
$\mathrm{CD}^{+}(\mathrm{SP}), \mathrm{CD}^{+}(\mathrm{SP}), \mathrm{CD}^{+} \mathrm{CD}^{+}$(DP) and $\mathrm{CD}^{-} \mathrm{CD}^{-}$(DP) in the thymus. Data are shown as mean $\pm \mathrm{SEM}$. Data are collected from 4-5 independent experiments with $5-6$ mice per group. ${ }^{*} P<.05,{ }^{* *} P<.01$, and ${ }^{* *} P<.001$. UTM: untreated transplanted mice (vehicle administration); IXZ: ixazomib group; HD: healthy donor; SYG: syngeneic group; $2 / 4$ and +10 W: weeks after starting the treatment. $P$ values were calculated using 1-way ANOVA and 2-sided Student's unpaired $t$-test. 


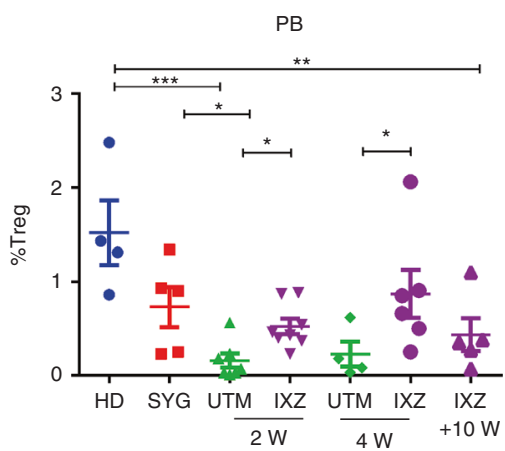

LN

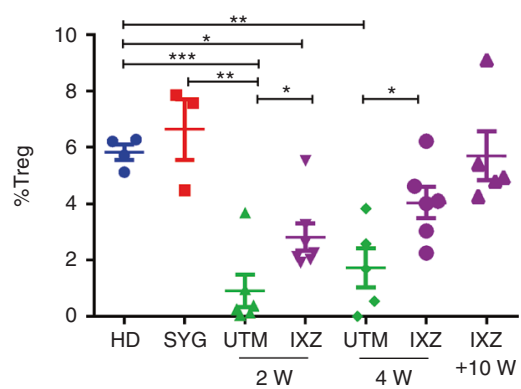

BM

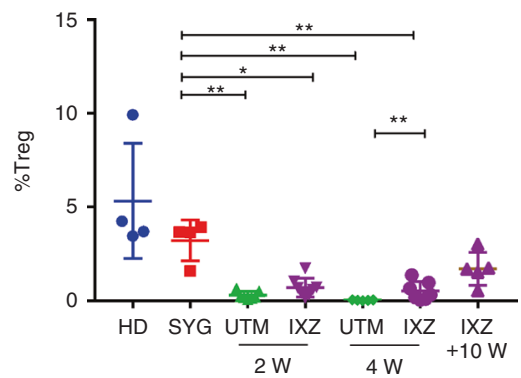

Lung

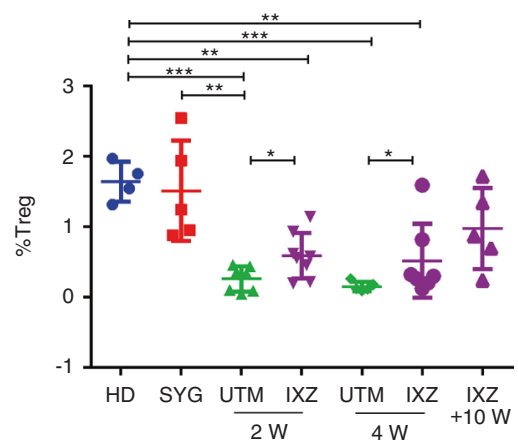

Spleen

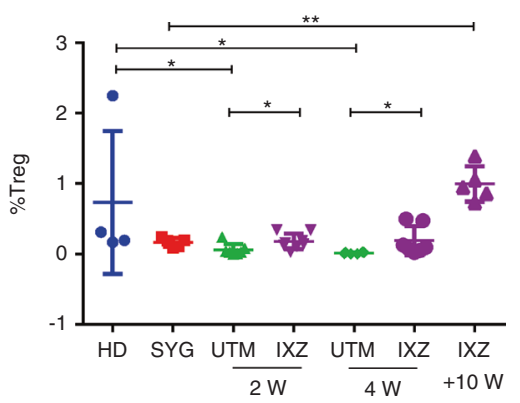

Colon

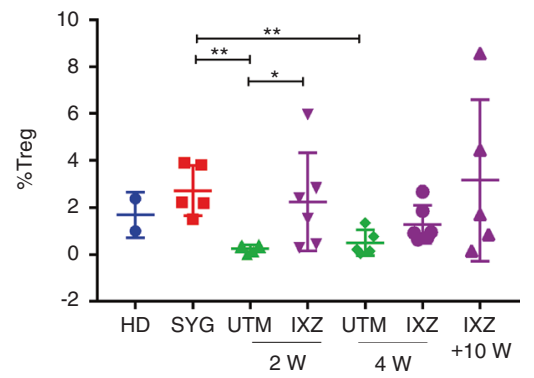

Fig. 3 Ixazomib treatment significantly increases the regulatory $\mathbf{T}$ cells. Percentage of Treg in $\mathrm{CD} 45^{+}$population $\left(C D 45^{+} \mathrm{CD} 3^{+} \mathrm{CD} 4^{+}\right.$ $\mathrm{CD} 25^{+} \mathrm{Foxp}^{+}$) in the different organs analyzed. Data are shown as mean \pm SEM. Data are collected from 4-5 independent experiments with 5-6 mice per group. ${ }^{*} P<.05,{ }^{* *} P<.01$, and ${ }^{* * *} P<.001$. UTM: untreated transplanted mice (vehicle administration); IXZ: ixazomib group; HD: healthy donor; SYG: syngeneic group; $2 / 4$ and $+10 \mathrm{~W}$ : weeks after starting the treatment. $P$ values were calculated using 1 -way ANOVA and 2-sided Student's unpaired $t$-test.

recovery of the regulatory $T$ cells was confirmed in the IXZ group along the 10 weeks of follow-up.

\section{Ixazomib enhances B cell recovery after transplantation and increases the Breg}

$B$ cell reconstitution takes weeks to months after allo-transplantation, with limited BCR diversity posttransplant [36]. In the pcGvHD model, we observed a decreased percentage of B cells (CD45 ${ }^{+}$ $\mathrm{CD} 9^{+}$) after transplant in the untreated mice (Fig. 4). Remarkably, mice receiving IXZ showed a significantly faster recovery in the percentage of $\mathrm{CD} 19^{+}$cells after 4 weeks in the different target organs analyzed, which was maintained at the long term (+10 weeks), Fig. 4A. Some authors have described a decrease of $B$ lineage-specific hematopoietic progenitor cells $\left(\mathrm{CD} 34^{+}\right.$ $\mathrm{CD} 9^{+}$) in CGvHD [37]. In our studies, the percentage of pre-pro$B$ cells (phenotypically defined as $\mathrm{B}_{2} 20^{+} \lg \mathrm{M}^{-} \lg \mathrm{D}^{-}$) in the $\mathrm{BM}$ was significantly decreased after allo-BMT. IXZ treated mice showed a significantly higher percentage of progenitor B cells as compared with UTM (Fig. 4).

\section{Ixazomib treatment modifies the recovery of myeloid cells post-transplant}

Myeloid cell populations including dendritic cells (DCs), neutrophils, macrophages, and certain monocytes subsets play a key role in the pathophysiology of GvHD. Using GR and CD1 1b markers we analyzed the percentage of polymorphonuclear cells (PMNs). After allo-transplantation, a significant increase of PMNs on the lymphoid and non-lymphoid organs was observed (Fig. 5). Interestingly, ixazomib treatment decreased the percentage of PMNs cells infiltrating the liver $(P=0.0140)$ and lung $(P=0.082)$ after 4 weeks of treatment or even sooner in some organs. The percentage of PMNs was similar in the IXZ group after 10 weeks of treatment as compared to the HD and SGY groups.

\section{Ixazomib decreases GvHD but maintains graft-versus- leukemia activity}

Once we confirmed the effect of IXZ, we aimed to determine its effect on graft-versus leukemia (GvL). For this purpose, mice were transplanted with A20-luc2 lymphoma cells together with $B M$, and with or without splenocytes. The group transplanted with $\mathrm{A} 20$ plus BM showed the worst survival, with all mice dying before day +80 (Fig. $6 \mathrm{~A}$ ). The survival curve slightly increased among mice also receiving splenocytes (Fig. 6A, red line). In this subgroup, lymphoma cells were detected for up to 4 weeks (Fig. 6B). Treatment with IXZ significantly increased overall survival $\left(\mathrm{BMT}+\mathrm{SC}+\mathrm{A} 20\right.$ vs. $\mathrm{BMT}+\mathrm{SC}+\mathrm{A} 20+\mathrm{IXZ} \quad{ }^{*} p=$ 0.0339 ). Remarkably, bioluminescence assays confirmed the elimination of tumor cells after 3 weeks among IXZ treated mice (Figs. $6 \mathrm{~A}$ and $6 \mathrm{~B}$ ). Next, we performed the same experiments adding cyclosporine $A$. Treatment with cyclosporine alone did not improve survival after transplant; by contrast, a significant improvement was observed upon using CsA and IXZ (BMT + $\mathrm{SC}+\mathrm{A} 20+\mathrm{CsA}$ vs. BMT $\left.+\mathrm{SC}+\mathrm{A} 20+\mathrm{CsA}+\mathrm{IXZ}{ }^{*} p=0.0307\right)$. The concentration of IXZ used in our study was not able (Fig. 6A, discontinued black line) to rescue the mice injected with $B M+$ A20 in the absence of splenocytes.

To further confirm the GvL effect of the T cells, we co-cultured the spleen cells from the mice that were transplanted with $\mathrm{BM}+$ $\mathrm{SC}+\mathrm{A} 20$ (with or without IXZ) with A20-GFP ${ }^{+}$cells. We observed a significant decrease of $A 20$ cells viability after exposure to T cells, which was more pronounced when A20 were co-cultured with lymphocytes from IXZ-treated mice (Fig. 6C). 

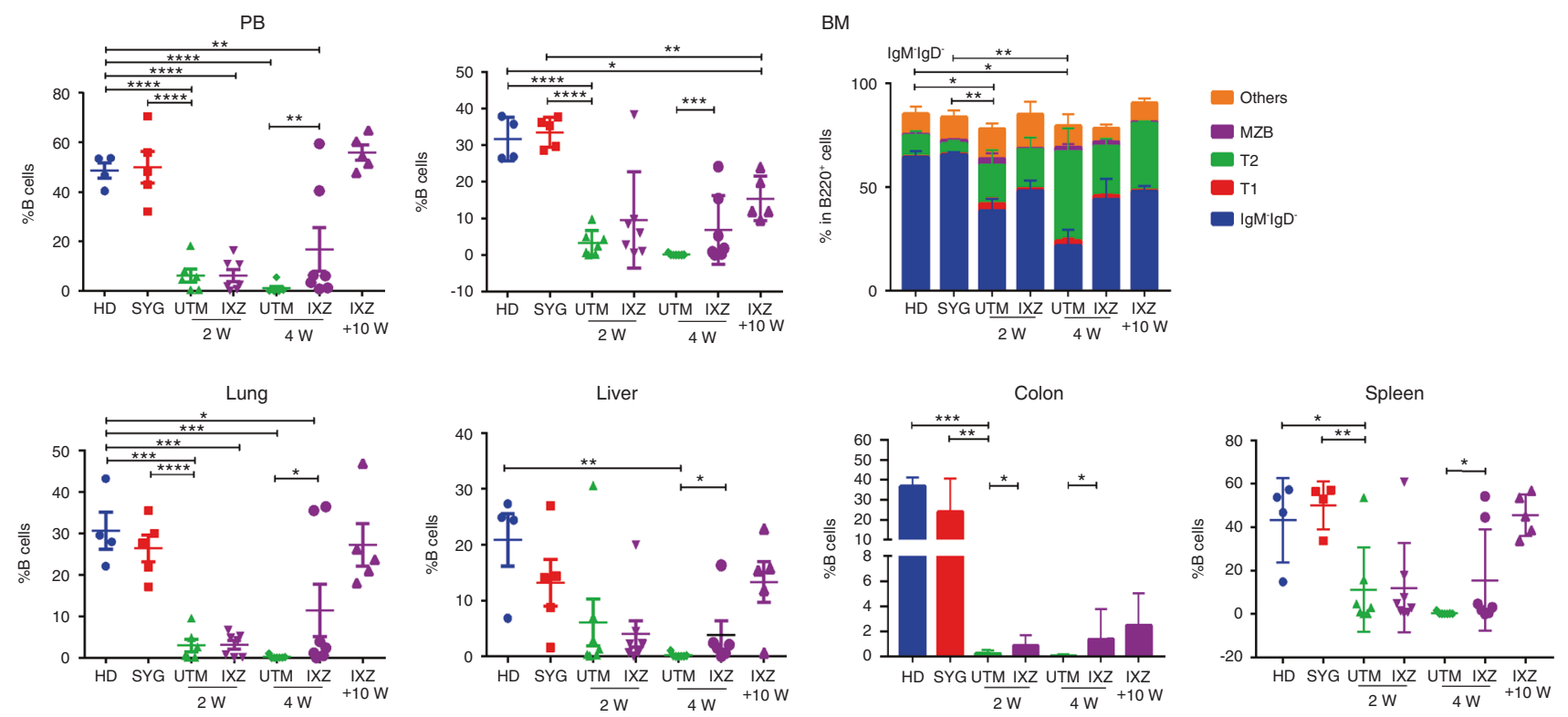

Fig. 4 Ixazomib treatment increases the recovery of B cells. Flow cytometry analysis of $B$ cells $\left(C D 45^{+} C D 19^{+}\right)$in the PB and in the different organs. The distribution of the different $B$ cell maturation in the BM panel represents the results from pcGVHD. Data are shown as mean \pm SEM. Data are collected from 4-5 independent experiments with 5-6 mice per group. ${ }^{*} P<.05$, ${ }^{* *} P<.01$, and ${ }^{* * *} P<.001$. 2-sided Student's unpaired $t$-test UTM: untreated transplanted mice (vehicle administration); IXZ: ixazomib group; HD: healthy donor; SYG: syngeneic group; $2 / 4$

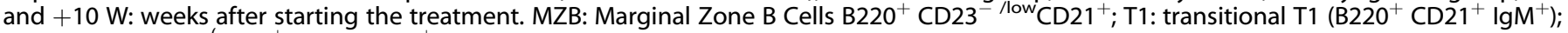
T2: transitional $\left.\mathrm{T} 2{ }^{(} \mathrm{B} 220^{+} \mathrm{CD} 21^{-} \operatorname{lgM}^{+}\right)$.

Our results demonstrate that IXZ can successfully ameliorate GvHD while maintaining a potent GvL effect.

\section{DISCUSSION}

Current approaches for GvHD prophylaxis are focused on specific maneuvers aimed to eliminate donor T cells early after transplant, with the hope that immune tolerance will spontaneously arise in the absence of alloreactive T cells. Nevertheless, as far as the pathophysiology of cGvHD is concerned, many different players must be considered in addition to T cells. Thus, active approaches might be designed to induce immune tolerance in the long term, with the potential advantage of maintaining enough $T$ cells from the donor capable to induce GvL. In our study, we hypothesized that IXZ treatment in the late posttransplant period ameliorates cGvHD, favors a protolerogenic immune reconstitution, and maintains GvL. While we and others have already reported the potential use of proteasome inhibitors in the GvHD setting, previous studies have focused on early post-transplant interventions. By contrast, in this study, we propose to evaluate whether it is possible to modulate the function of the different cell subsets involved in CGvHD pathophysiology, promoting a pro-tolerogenic immune response in the long term.

To test this hypothesis, we used a progressive chronic GvHD model applying a major histocompatibility antigen mismatched. The mice were transplanted with progenitor cells and low numbers of splenocytes. In this model, the mice started to develop the characteristic of acute clinical signs around day 21 posttransplant, and those surviving this acute phase subsequently stabilized their weight and develop chronic signals. This is in accordance with previous reports showing that low-dose donor spleen cells allow the mice to survive aGvHD, and promote the expansion of autoreactive T cells and the development of cGVHD [30]. Thus, these findings resemble the typical outcome of a progressive chronic GvHD in the clinical setting, which was confirmed in the histopathological examination. For the sclerodermatous CGvHD model, we applied a minor histocompatibility antigen mismatched model.
The progressive chronic GvHD mouse model recapitulates the immunologic features described after allo-HSCT [38]. More specifically, regarding T cells, in the pcGvHD model, we confirmed an abnormal $\mathrm{CD} 4^{+} / \mathrm{CD}^{+}$proportion and a significant increase in the effector $T$ cell numbers, as previously described [39]. This pattern was not only observed in the PB, but also in GvHD target organs.

The thymus is the primary organ for tolerance induction and the development of T-lymphocytes. Previous studies have described that thymic damage after allo-HSCT results in a defective negative selection [40]. In our study, a significant reduction in the percentage of $\mathrm{CD}^{+}{ }^{+} \mathrm{CD} 8^{+}$thymocytes (DP), a distinctive hallmark of thymus damage was observed in UTM mice [35]. IXZ group showed a significant increase in this population. GvHD is characterized by an imbalance between effector and regulatory immune function. Interestingly, ixazomib treatment in the context of chronic GvHD evolution was able to decrease the effector $\mathrm{T}$ cells and increase the percentage of regulatory cells. Our data confirm our previous studies describing the capacity of the proteasome inhibitor to preserve regulatory $T$ cells while abrogating activated conventional T cells viability [21], but with this study, we showed this capacity also in the GvHD target organs.

In the post-HSCT, the alloantigen-rich microenvironment leads to aberrant activation of $T$ and $B$ cells, a characteristic signature of cGvHD [41].

As far as the B cell recovery is concerned, previous studies have shown that, within germinal centers, donor B cells produce autoantibodies which are responsible for the development of sclerotic manifestations of CGvHD [13, 42]. Different models have described the loss of the $\mathrm{B}$ cell pool in the $\mathrm{BM}$ and periphery during GvHD. Kolupaev et al. (2018) [43] found decreased numbers of common lymphoid progenitor (CLPs) pro-pre-B cells and immature $B$ cells in the BM within a bronchiolitis obliterans syndrome (BOS) mouse model of cGvHD. The mechanism responsible for this abnormal $B$ cell development was explained because of the donor CD4+ T cells infiltrating the BM. They also observed that Treg cells can revert the effects of donor T cells on B 
a

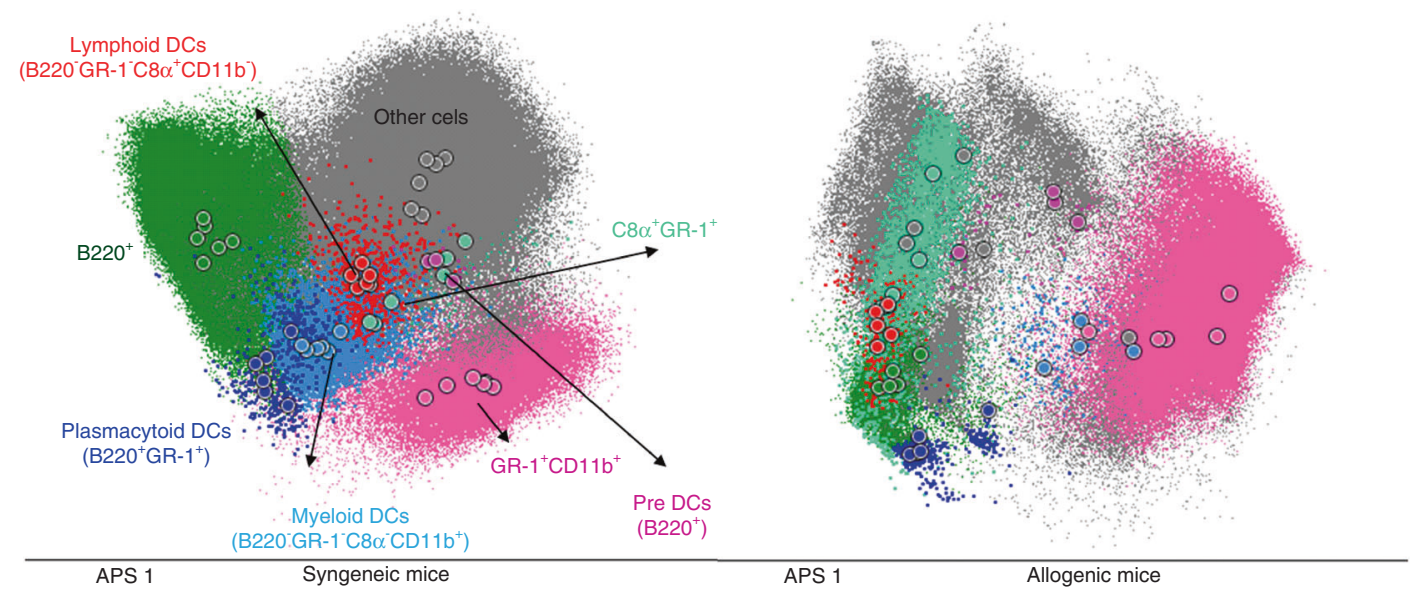

b

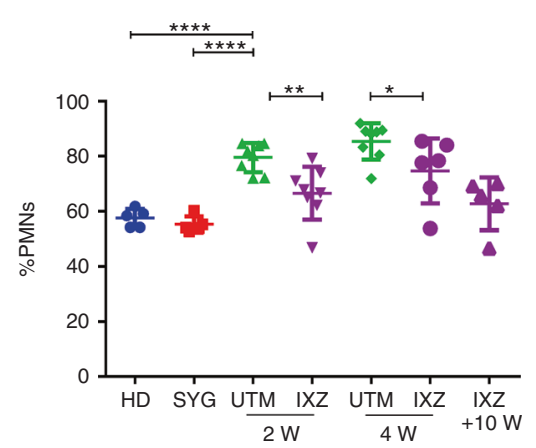

LN

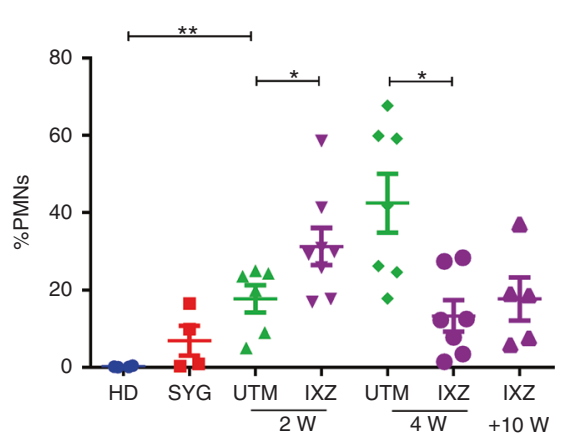

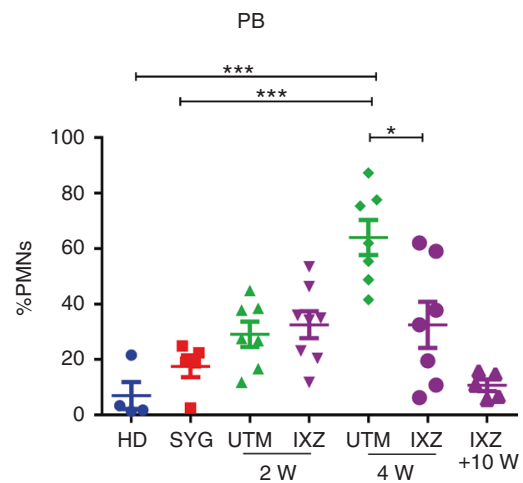
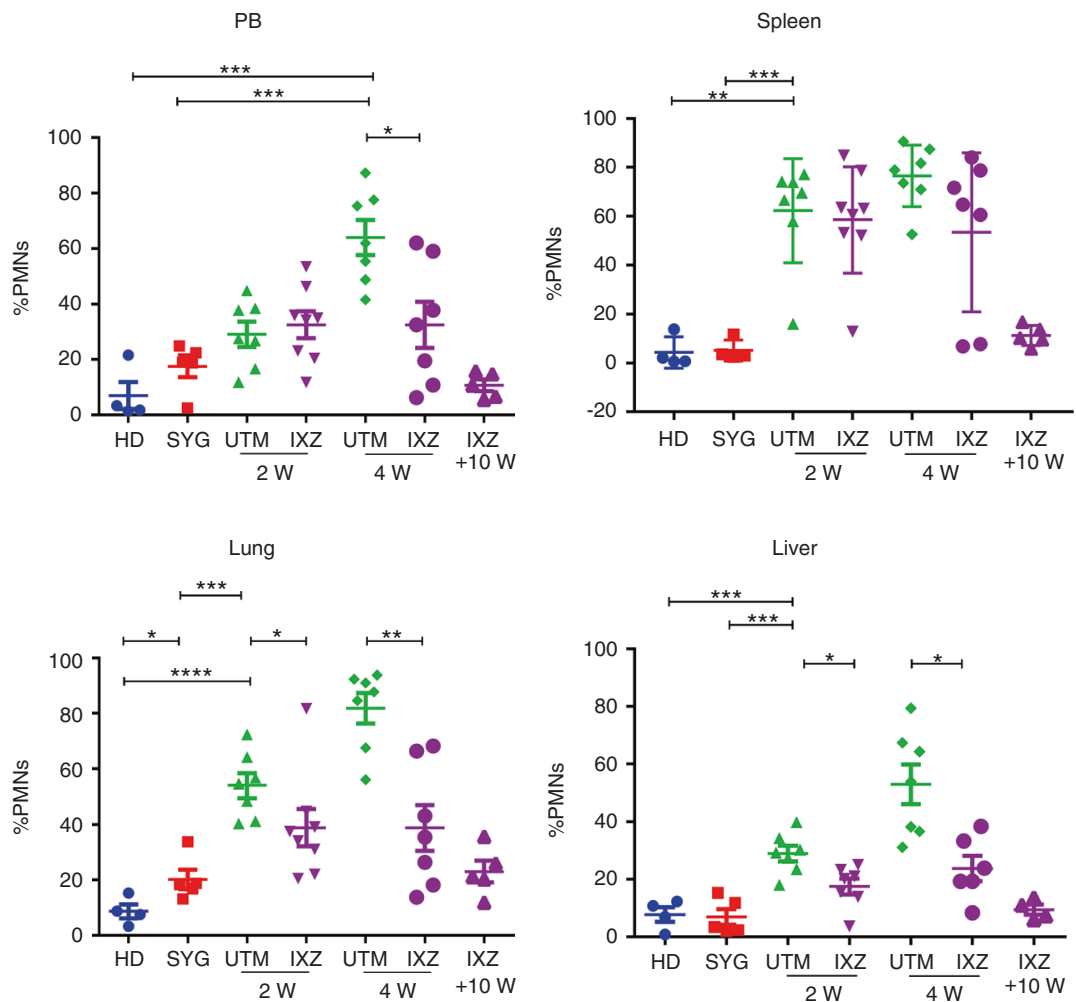

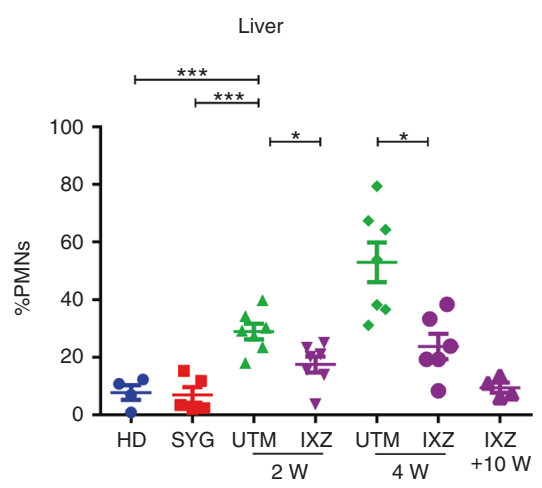

Fig. 5 Myeloid population after transplantation in pcGvHD model. Flow cytometry assays of the different organs at different time points after treatment were performed. a Automatic population separation (APS) representative figure of HD and UTM. b PMNs (GR-1 $1^{+}$CD11 ${ }^{+}$) in the different GvHD target organs. Data are collected from 4-5 independent experiments with 5-6 mice per group. Data are shown as mean \pm SEM. ${ }^{*} P<.05,{ }^{* *} P<.01$, and ${ }^{* * *} P<.001$. $P$ values were calculated using 1-way ANOVA (b). UTM: untreated transplanted mice (vehicle administration); IXZ: ixazomib group; HD: healthy donor; SYG: syngeneic group; $2 / 4$ and +10 W: weeks after starting the treatment.; PMNs: polymorphonuclear cells.

cell development in the BM. In our pcGvHD model, treatment with IXZ fostered B cell regeneration by increasing the percentage of pre-pro-B cells in BM. Again, these results agree with previous studies [43]. Remarkably, mice receiving IXZ reached a pattern like the control group significantly sooner than UTM both for B cells and for pre-pro-B cells.

Concerning myeloid populations, there is evidence that neutrophils play a key role in the pathophysiology of GvHD $[44,45]$. Recent studies showed their multifaceted activities, where they can also function as key effectors in the innate and adaptative immune response with the capacity of prime $\mathrm{T}$ cells activation both in vitro and in vivo $[46,47]$. In the acute GvHD animal model, the treatment with antibody mediates (anti-Ly6G) or genetically determined depletion of neutrophils was found to reduce aGvHD aggressiveness and mortality [48]. In chronic GvHD, neutrophils are hypothesized to be involved in ocular cGvHD pathogenesis in patients, mainly via their release of neutrophil extracellular traps (NETs) [49]. IXZ was able to decrease the number of neutrophils in the GvHD target organs, future studies will be important to address the effect of ixazomib on the eventual possibility of modulating their function in allo-HSCT.

In summary, we were able to ameliorate chronic GvHD while preserving GVL response by delaying IXZ administration. Ixazomib treatment was able to modify the immune system with a faster 


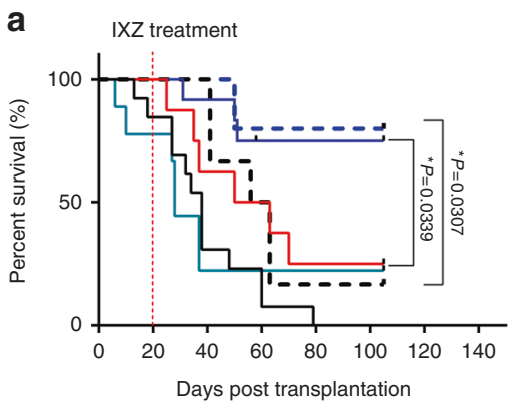

$$
\begin{aligned}
& \text { - } \mathrm{BMT}+\mathrm{A} 20 \\
& \text { - } \mathrm{BMT}+\mathrm{SC}+\mathrm{A} 20 \\
& \text { - } \mathrm{BMT}+\mathrm{SC}+\mathrm{A} 20+\mathrm{IXZ} \\
& \text { - } \mathrm{BMT}+\mathrm{SC}+\mathrm{A} 20+\mathrm{CsA} \\
& \text {-- } \mathrm{BMT}+\mathrm{A} 20+I X Z \\
& \text {-- BMT+SC+A20+CsA+IXZ }
\end{aligned}
$$

Days post transplantation

C
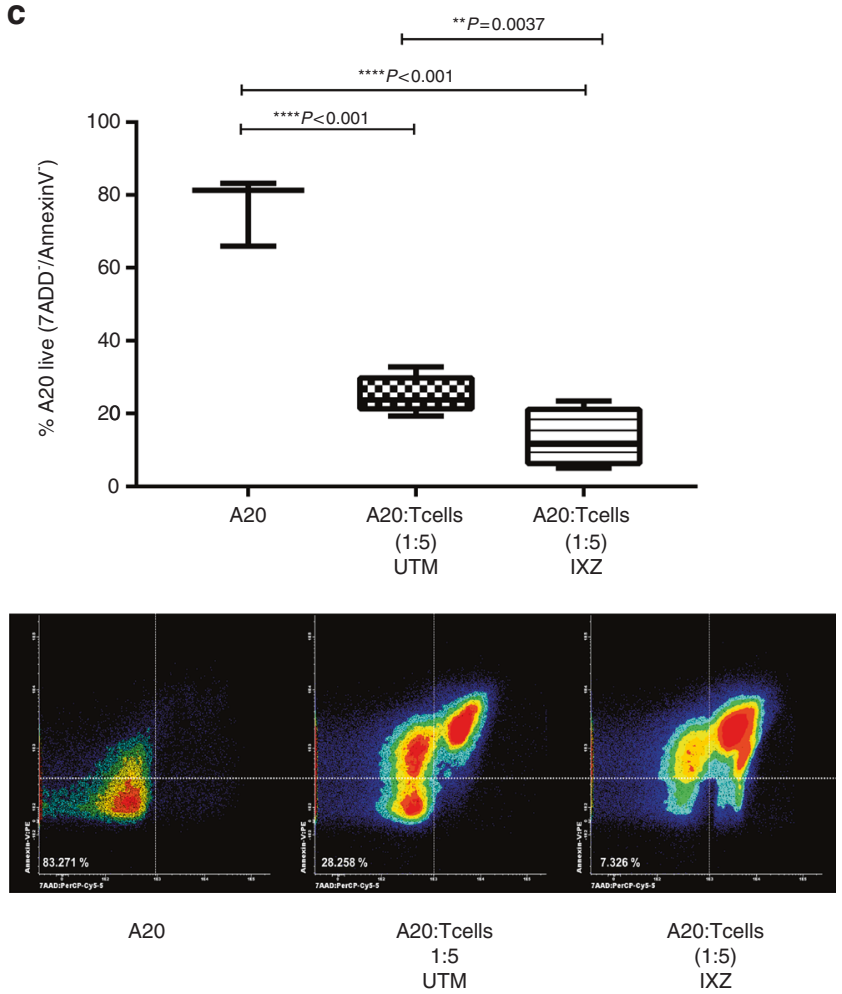

b

$\mathrm{BMT}+\mathrm{A} 20-$ luc2-GFP

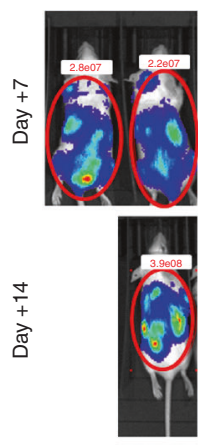

$\stackrel{+}{+}$

๙ิ

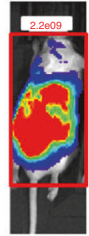

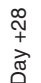

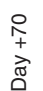

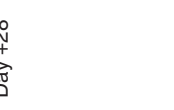

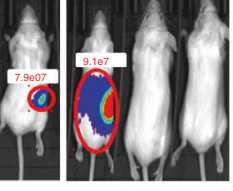
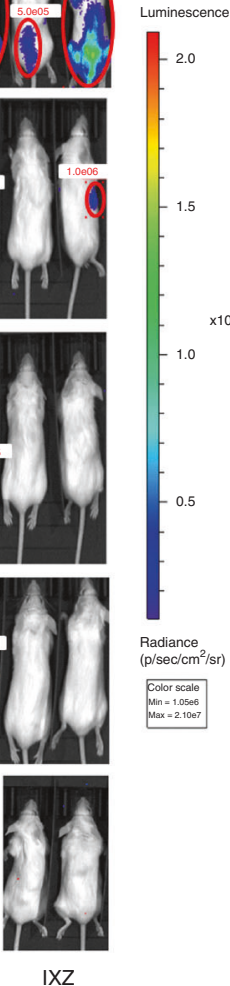

UTM

$X Z$

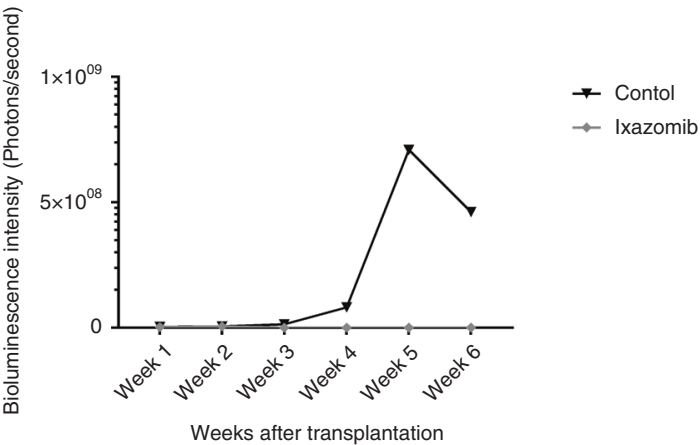

Fig. 6 Ixazomib administration protects mice from pcGvHD while maintaining a potent GvL effect. Irradiated BALB/C mice were transplanted with BM and A20 luciferase-transfected lymphoma cells with or without spleen cells at day 0. (A) Survival curves of mice receiving IXZ at $1 \mathrm{mg} / \mathrm{Kg}$, two times per week sc. from day +21 post-transplantation or vehicle (UTM), and IXZ plus cyclosporine $A$ (CsA) (at $5 \mathrm{mg} / \mathrm{Kg}$, intraperitoneally, 5 days a week from day -5) or CsA alone. B Bioluminescent images were acquired to monitor tumor burden. C Viability (annexin $\mathrm{V}^{-} / 7 \mathrm{AAD}^{-}$) of $\mathrm{A} 20$ cells that was co-cultured for $18 \mathrm{~h}$ with splenocytes (ration 1:5) obtained from UTM or IXZ treated mice transplanted with BM, spleen cells, and A20 cells. Data were collected from 2 independent experiments with 3-4 mice per group ( $n=7-8$ ). Data are shown as mean \pm SEM. ${ }^{*} P<.05,{ }^{* *} P<.01$, and ${ }^{* * *} P<.001$. Survival data were plotted by the Kaplan-Meier method and analyzed by the log-rank test. $P$ values were calculated using a one-way ANOVA test (C). UTM: untreated transplanted mice; IXZ: ixazomib group.

recovery of the different cell subpopulations analyzed favoring a more pro-tolerogenic immune response. An ongoing clinical trial aims to determine the effects of ixazomib in patients undergoing allo-HSCT.

\section{REFERENCES}

1. Dignan FL, Amrolia P, Clark A, Cornish J, Jackson G, Mahendra P, et al. Diagnosis and management of chronic graft-versus-host disease. $\mathrm{Br} J$ Haematol. 2012;158:46-61. https://doi.org/10.1111/j.1365-2141.2012.09128.x.
2. Perez-Simon JA, Sanchez-Abarca I, Diez-Campelo M, Caballero D, San Miguel J. Chronic graft-versus-host disease: Pathogenesis and clinical management. Drugs. 2006:66:1041-1057. https://doi.org/10.2165/00003495-200666080-00002.

3. Pérez-Simón JA, Afram G, Martino R, Piñana JL, Caballero-Velazquez T, Ringden O, et al. Evaluation of prognostic factors among patients with chronic graft-versushost disease. Haematologica. 2012;97:1187-1195. https://doi.org/10.3324/ haematol.2011.055244.

4. Stem Cell Trialists' Collaborative G. Allogeneic peripheral blood stem-cell compared with bone marrow transplantation in the management of hematologic malignancies: an individual patient data meta-analysis of nine randomized trials. J Clin Oncol. 2005;23:5074-5087. https://doi.org/10.1200/JCO.2005.09.020. 
5. Cutler CS, Koreth J, Ritz J. Mechanistic approaches for the prevention and treatment of chronic GVHD. Blood. 2017;129:22-29. https://doi.org/10.1182/ blood-2016-08-686659.

6. Pidala J, Kurland B, Chai X, Majhail N, Weisdorf DJ, Pavletic S, et al. Patientreported quality of life is associated with severity of chronic graft-versus-host disease as measured by NIH criteria: report on baseline data from the Chronic GVHD Consortium. Blood. 2011;117:4651-4657. https://doi.org/10.1182/blood2010-11-319509.

7. Im A, Hakim FT, Pavletic SZ. Novel targets in the treatment of chronic graft-versushost disease. Leukemia. 2017;31:543-554. https://doi.org/10.1038/leu.2016.367.

8. Kröger N, Solano C, Wolschke C, Bandini G, Patriarca F, Pini M, et al. Antilymphocyte globulin for prevention of chronic graft-versus-host disease. N. Engl J Med. 2016;374:43-53. https://doi.org/10.1056/NEJMoa1506002.

9. McCurdy SR, Fuchs EJ. Comparable outcomes for hematologic malignancies after HLA-haploidentical transplantation with posttransplantation cyclophosphamide and HLA-matched transplantation. Adv Hematol. 2015;2015:431923 https://doi. org/10.1155/2015/431923.

10. Chang YJ, Zhao XY, Huang XJ. Strategies for enhancing and preserving antileukemia effects without aggravating graft-versus-host disease. Front Immunol. 2018;9:3041 https://doi.org/10.3389/fimmu.2018.03041.

11. Flowers ME, Inamoto $Y$, Carpenter PA, Lee SJ, Kiem HP, Petersdorf EW, et al. Comparative analysis of risk factors for acute graft-versus-host disease and for chronic graft-versus-host disease according to National Institutes of Health consensus criteria. Blood. 2011;117:3214-3219. https://doi.org/10.1182/blood2010-08-302109.

12. Saidu NEB, Bonini C, Dickinson A, Grce $M$, Inngjerdingen $M$, Koehl $U$, et al. New approaches for the treatment of chronic graft-versus-host disease: current status and future directions. Front Immunol. 2020;11:578314 https://doi.org/10.3389/ fimmu.2020.578314.

13. Zeiser R, Blazar BR. Pathophysiology of chronic graft-versus-host disease and therapeutic targets. N Engl J Med. 2017;377:2565-2579. https://doi.org/10.1056/ NEJMra1703472.

14. Zeiser R. Advances in understanding the pathogenesis of graft-versus-host disease. Br J Haematol. 2019;187:563-572. https://doi.org/10.1111/bjh.16190.

15. Presland RB. Biology of chronic graft-vs-host disease: immune mechanisms and progress in biomarker discovery. World J Transpl. 2016;6:608-619. https://doi.org/ 10.5500/wjt.v6.i4.608.

16. Cooke KR, Luznik L, Sarantopoulos S, Hakim FT, Jagasia M, Fowler DH, et al. The biology of chronic graft-versus-host disease: a task force report from the national institutes of health consensus development project on criteria for clinical trials in chronic graft-versus-host disease. Biol Blood Marrow Transpl. 2017;23:211-234. https://doi.org/10.1016/j.bbmt.2016.09.023.

17. Hayden MS, Ghosh S. NF-kappaB in immunobiology. Cell Res. 2011;21:223-244. https://doi.org/10.1038/cr.2011.13.

18. Sen R. Control of B lymphocyte apoptosis by the transcription factor NF-kappaB. Immunity. 2006:25:871-883. https://doi.org/10.1016/j.immuni.2006.12.003.

19. Zhu M, Fu Y. The complicated role of NF-kappaB in T-cell selection. Cell Mol Immunol. 2010;7:89-93. https://doi.org/10.1038/cmi.2009.112.

20. Blanco B, Pérez-Simón JA, Sánchez-Abarca LI, Carvajal-Vergara X, Mateos J, Vidriales B, et al. Bortezomib induces selective depletion of alloreactive $T$ lymphocytes and decreases the production of Th1 cytokines. Blood. 2006;107:3575-3583. https://doi. org/10.1182/blood-2005-05-2118.

21. Blanco B, Pérez-Simón JA, Sánchez-Abarca LI, Caballero-Velazquez T, GutierrezCossío S, Hernández-Campo $\mathrm{P}$, et al. Treatment with bortezomib of human CD4+ $T$ cells preserves natural regulatory $T$ cells and allows the emergence of a distinct suppressor T-cell population. Haematologica. 2009;94:975-983. https://doi.org/ 10.3324/haematol.2008.005017.

22. Blanco B, Sanchez-Abarca LI, Caballero-Velazquez T, Santamaria C, Inoges S, Perez-Simon JA. Depletion of alloreactive T-cells in vitro using the proteasome inhibitor bortezomib preserves the immune response against pathogens. Leuk Res. 2011;35:1412-1415. https://doi.org/10.1016/j.leukres.2011.05.018.

23. Caballero-Velázquez T, Sánchez-Abarca LI, Gutierrez-Cosio S, Blanco B, Calderon $C$, Herrero $C$, et al. The novel combination of sirolimus and bortezomib prevents graft-versus-host disease but maintains the graft-versus-leukemia effect after allogeneic transplantation. Haematologica. 2012;97:1329-1337. https://doi.org/ 10.3324/haematol.2011.058677.

24. Caballero-Velázquez T, Calderón-Cabrera C, López-Corral L, Puig N, MarquezMalaver F, Pérez-López $\mathrm{E}$, et al. Efficacy of bortezomib to intensify the conditioning regimen and the graft-versus-host disease prophylaxis for high-risk myeloma patients undergoing transplantation. Bone Marrow Transpl. 2020;55:419-430. https://doi.org/10.1038/s41409-019-0670-6.

25. Pai CC, Chen M, Mirsoian A, Grossenbacher SK, Tellez J, Ames E, et al. Treatment of chronic graft-versus-host disease with bortezomib. Blood. 2014;124:1677-1688. https://doi.org/10.1182/blood-2014-02-554279.
26. Richardson PG, Baz R, Wang M, Jakubowiak AJ, Laubach JP, Harvey RD, et al. Phase 1 study of twice-weekly ixazomib, an oral proteasome inhibitor, in relapsed/refractory multiple myeloma patients. Blood. 2014;124:1038-1046. https://doi.org/10.1182/blood-2014-01-548826.

27. Al-Homsi AS, Goodyke A, Cole K, Muilenburg M, McLane M, Abdel-Mageed S, et al. Ixazomib suppresses human dendritic cell and modulates murine graft-versus-host disease in a schedule-dependent fashion. Exp Hematol. 2017;48:50-57. https://doi. org/10.1016/j.exphem.2016.12.002

28. Al-Homsi AS, Goodyke A, McLane M, Abdel-Mageed S, Cole K, Muilenburg M, et al. Post-transplantation cyclophosphamide and ixazomib combination rescues mice subjected to experimental graft-versus-host disease and is superior to either agent alone. Biol Blood Marrow Transpl. 2017;23:255-261. https://doi.org/ 10.1016/j.bbmt.2016.11.015.

29. Okabe M, Ikawa M, Kominami K, Nakanishi T, Nishimune Y. 'Green mice' as a source of ubiquitous green cells. FEBS Lett. 1997;407:313-319. https://doi.org/ 10.1016/s0014-5793(97)00313-x.

30. Wu T, Young JS, Johnston $H$, Ni X, Deng $R$, Racine J, et al. Thymic damage, impaired negative selection, and development of chronic graft-versus-host disease caused by donor CD4+ and CD8+ T cells. J Immunol. 2013;191:488-499. https://doi.org/10.4049/jimmunol.1300657.

31. Zhao D, Young JS, Chen YH, Shen E, Yi T, Todorov I, et al. Alloimmune response results in expansion of autoreactive donor CD4+ T cells in transplants that can mediate chronic graft-versus-host disease. J Immunol. 2011;186:856-868. https:// doi.org/10.4049/jimmunol.1002195.

32. Alvarez-Laderas I, Ramos TL, Medrano M, Caracuel-García R, Barbado MV, Sánchez-Hidalgo $\mathrm{M}$, et al. Polyphenolic extract $(\mathrm{PE})$ from olive oil exerts a potent immunomodulatory effect and prevents graft-versus-host disease in a mouse model. Biol Blood Marrow Transpl. 2020;26:615-624. https://doi.org/10.1016/j. bbmt.2019.11.019.

33. Carrancio S, Romo C, Ramos T, Lopez-Holgado N, Muntion S, Prins HJ, et al. Effects of MSC coadministration and route of delivery on cord blood hematopoietic stem cell engraftment. Cell Transpl. 2013;22:1171-1183. https://doi.org/10.3727/ 096368912 X657431.

34. Chu YW, Gress RE. Murine models of chronic graft-versus-host disease: insights and unresolved issues. Biol Blood Marrow Transpl. 2008;14:365-378. https://doi. org/10.1016/j.bbmt.2007.12.002.

35. Hollander GA, Widmer B, Burakoff SJ. Loss of normal thymic repertoire selection and persistence of autoreactive $T$ cells in graft vs host disease. J Immunol. 1994;152:1609-1617.

36. Shimabukuro-Vornhagen A, Hallek MJ, Storb RF, von Bergwelt-Baildon MS. The role of $B$ cells in the pathogenesis of graft-versus-host disease. Blood. 2009;114:4919-4927. https://doi.org/10.1182/blood-2008-10-161638.

37. Michonneau D, Peffault de Latour R, Porcher R, Robin M, Benbunan M, Rocha V, et al. Influence of bone marrow graft B lymphocyte subsets on outcome after HLA-identical sibling transplants. Br J Haematol. 2009;145:107-114. https://doi. org/10.1111/j.1365-2141.2008.07574.x.

38. Ogonek J, Kralj Juric M, Ghimire S, Varanasi PR, Holler E, Greinix H, et al. Immune reconstitution after allogeneic hematopoietic stem cell transplantation. Front Immunol. 2016;7:507 https://doi.org/10.3389/fimmu.2016.00507.

39. Teshima T, Reddy $P$, Zeiser R. Acute graft-versus-host disease: novel biological insights. Biol Blood Marrow Transpl. 2016;22:11-16. https://doi.org/10.1016/j. bbmt.2015.10.001.

40. Teshima T, Reddy P, Liu C, Williams D, Cooke KR, Ferrara JL. Impaired thymic negative selection causes autoimmune graft-versus-host disease. Blood. 2003;102:429-435. https://doi.org/10.1182/blood-2003-01-0266.

41. MacDonald KP, Hill GR, Blazar BR. Chronic graft-versus-host disease: biological insights from preclinical and clinical studies. Blood. 2017;129:13-21. https://doi. org/10.1182/blood-2016-06-686618.

42. Sarantopoulos S, Blazar BR, Cutler C, Ritz J. B cells in chronic graft-versus-host disease. Biol Blood Marrow Transpl. 2015;21:16-23. https://doi.org/10.1016/j. bbmt.2014.10.029.

43. Kolupaev OV, Dant TA, Bommiasamy H, Bruce DW, Fowler KA, Tilley SL, et al. Impaired bone marrow B-cell development in mice with a bronchiolitis obliterans model of cGVHD. Blood Adv. 2018;2:2307-2319. https://doi.org/10.1182/ bloodadvances.2017014977.

44. Hülsdünker J, Ottmüller KJ, Neeff HP, Koyama $M$, Gao Z, Thomas $O S$, et al. Neutrophils provide cellular communication between ileum and mesenteric lymph nodes at graft-versus-host disease onset. Blood. 2018;131:1858-1869. https://doi.org/10.1182/blood-2017-10-812891.

45. Martin PJ. Pathogenic neutrophils in acute GVHD. Blood. 2018;131:1774-1775 https://doi.org/10.1182/blood-2018-03-836353.

46. Beauvillain C, Delneste $Y$, Scotet $M$, Peres A, Gascan $H$, Guermonprez $P$, et al. Neutrophils efficiently cross-prime naive $T$ cells in vivo. Blood. 2007;110:2965-2973. https://doi.org/10.1182/blood-2006-12-063826. 
47. Ostanin DV, Kurmaeva E, Furr K, Bao R, Hoffman J, Berney S, et al. Acquisition of antigen-presenting functions by neutrophils isolated from mice with chronic colitis. J Immunol. 2012;188:1491-1502. https://doi.org/10.4049/jimmunol.1102296.

48. Schwab L, Goroncy L, Palaniyandi S, Gautam S, Triantafyllopoulou A, Mocsai A, et al. Neutrophil granulocytes recruited upon translocation of intestinal bacteria enhance graft-versus-host disease via tissue damage. Nat Med. 2014;20:648-654. https://doi.org/10.1038/nm.3517.

49. An S, Raju I, Surenkhuu B, Kwon JE, Gulati S, Karaman M, et al. Neutrophil extracellular traps (NETs) contribute to pathological changes of ocular graft-vs.host disease (oGVHD) dry eye: Implications for novel biomarkers and therapeutic strategies. Ocul Surf. 2019;17:589-614. https://doi.org/10.1016/j.jtos.2019.03.010.

\section{ACKNOWLEDGEMENTS}

Takeda company (PCRS-2016-101751) partially supported the study; This work has been partially supported by the CIBERONC (CB16/12/00480), and TerCel 16/0011/ 0035. Spanish Association Against Cancer (AECC-POSTD18023LOPE) fellowship (TLR).

\section{AUTHOR CONTRIBUTIONS}

TLR, EGG, RCG and MN. performed experiments; TLR, TCV, MVB, and ARG analyzed results and made the figures; MJRF analyzed the histology; TLR and JAPS designed the research and wrote the paper. All the authors read and approved the final manuscript.

\section{COMPETING INTERESTS}

The authors declare no competing interests.

\section{ADDITIONAL INFORMATION}

Supplementary information The online version contains supplementary material available at https://doi.org/10.1038/s41409-021-01452-1.

Correspondence and requests for materials should be addressed to José A. PérezSimón.

Reprints and permission information is available at http://www.nature.com/ reprints

Publisher's note Springer Nature remains neutral with regard to jurisdictional claims in published maps and institutional affiliations.

(i) Open Access This article is licensed under a Creative Commons Attribution 4.0 International License, which permits use, sharing, adaptation, distribution and reproduction in any medium or format, as long as you give appropriate credit to the original author(s) and the source, provide a link to the Creative Commons licence, and indicate if changes were made. The images or other third party material in this article are included in the article's Creative Commons licence, unless indicated otherwise in a credit line to the material. If material is not included in the article's Creative Commons licence and your intended use is not permitted by statutory regulation or exceeds the permitted use, you will need to obtain permission directly from the copyright holder. To view a copy of this licence, visit http://creativecommons. org/licenses/by/4.0/.

(c) The Author(s) 2021 